Article

\title{
Enablers and Barriers to Online Learning among Medical Students during COVID-19 Pandemic: An Explanatory Mixed-Method Study
}

\author{
Nurhanis Syazni Roslan ${ }^{1}$ and Ahmad Sukari Halim ${ }^{2,3, *(D)}$ \\ 1 Department of Medical Education, School of Medical Sciences, Health Campus, Universiti Sains Malaysia, \\ Kubang Kerian 16150, Malaysia; nurhanis_syazni@usm.my \\ 2 Reconstructive Sciences Unit, School of Medical Sciences, Health Campus, Universiti Sains Malaysia, \\ Kubang Kerian 16150, Malaysia \\ 3 Hospital Universiti Sains Malaysia, Kubang Kerian 16150, Malaysia \\ * Correspondence: ashalim@usm.my
}

Citation: Roslan, N.S.; Halim, A.S. Enablers and Barriers to Online Learning among Medical Students during COVID-19 Pandemic: An Explanatory Mixed-Method Study. Sustainability 2021, 13, 6086. https:// doi.org/10.3390/su13116086

Academic Editor: Jorge

Martin Gutierrez

Received: 30 April 2021

Accepted: 27 May 2021

Published: 28 May 2021

Publisher's Note: MDPI stays neutral with regard to jurisdictional claims in published maps and institutional affiliations.

Copyright: (c) 2021 by the authors. Licensee MDPI, Basel, Switzerland. This article is an open access article distributed under the terms and conditions of the Creative Commons Attribution (CC BY) license (https:// creativecommons.org/licenses/by/ $4.0 /)$.

\begin{abstract}
As the coronavirus disease 2019 (COVID-19) trajectory remains unknown, online learning (OL) has replaced face-to-face teaching strategies in education institutions. Research and training focus on harnessing educators, but less is understood at the students' ends. This study examines the OL readiness components, self-regulation, enablers, and barriers to OL at home among medical students during the COVID-19 pandemic through an explanatory mixed-method study. We conducted a cross-sectional study with 178 students and an in-depth interview with 10 students from a public medical school in Malaysia. We found that while all students owned at least one learning device, $22.5 \%$ of the students did not have a learning space at home. $21.9 \%$ students did not have Wi-Fi access, and $11.2 \%$ did not receive mobile broadband coverage at home. Despite these barriers, students had a suitable OL self-regulation level. Significantly higher self-regulation was observed among pre-clinical year students, students with higher grades, and students who had designated learning space at home. We found that high-immediacy and low-bandwidth applications such as WhatsApp and Telegram, and YouTube as the most accessible and easiest platforms to navigate in OL. Our qualitative findings yielded a conceptual model of OL enablers at learners, educators, and institution levels. This framework may serve as one of the guides in faculty development planning and policymaking, especially in promoting a more socially inclusive OL.
\end{abstract}

Keywords: online learning; e-learning; blended learning; distance education; COVID-19; selfregulation; online learning readiness; sustainable medical education

\section{Introduction}

Online learning (OL) is defined as the access to the learning experience by the use of technology networks [1]. It is deemed as the newer version of distance learning, and terms such as online teaching, digital learning, web-based, and e-learning are used interchangeably with OL in the literature. OL can be broadly categorized as synchronous (real-time teaching activities), asynchronous (pre-recorded or non-real-time teaching activities), and hybrid (mixture of synchronous and asynchronous). Synchronous OL can be conducted through applications such as Microsoft Teams, Zoom, Google Meet, and Telegram. Asynchronous OL can be conducted through a broader range of applications that include Massive Open Online Course (MOOC), Moodle, Blackboard, pre-recorded PowerPoint presentation, audio files, YouTube, and e-mail [2,3].

Over the last decade, OL has evolved rapidly due to its convenience. Prior to coronavirus disease 2019 (COVID-19), most higher education institutions were still relying on face-to-face teaching mode with OL offered for distance education or as a supplement to the conventional teaching. However, since the COVID-19 pandemic was declared on 
11 March 2020 [4], over 87\% of students around the globe were impacted by the lockdown measures and prolonged closure of education institutions [2]. With the pandemic trajectory remain unknown, OL has become an emergency measure to replace face-to-face teaching in education institutions [5].

A model of OL readiness builds upon seven S factors-strategy, structure, systems, style or culture, staff, skills, and shared value [6,7]. However, many institutions focused on training the educators to deliver OL effectively, evident by the huge numbers of articles on online learning innovations. Less is understood on the dynamic of OL from the learners' side in the context of the pandemic [8]. Components of the OL readiness model that may affect the students' experience include systems and skills. Systems are the formal and informal elements that support the delivery of OL strategy and its structure [6]. This includes technology (Internet access and learning device availability at home) and OL platform supports. While students enjoyed free Wi-Fi access through university hotspots during their stay on the campus, some students might not have access to the Internet at home. The Malaysian Communications and Multimedia Commission (MCMC) report found that only $90.1 \%$ of Malaysians have Internet coverage at home [9]. In contrast to the conventional teaching where students gathered in a venue and had access to immediate support by educators, studies found that students face technical difficulties at home when navigating through OL platforms $[10,11]$. This emphasizes that skills matter not only to the educators and support staff but also to the students as the users of OL [7].

As OL places greater responsibility on students to take control of their learning process, self-regulated learning is a critical factor for the success of OL [12]. Self-regulation is the "self-generated thoughts, feelings, and actions that are planned and cyclically adapted to the attainment of personal goals" [13]. A study among university students found that self-regulation and locus of control were the significant discriminating factors between students who complete online courses and dropouts [14]. Self-regulation has also been found as one of the best predictors of academic success in both face-to-face and online learning programs $[15,16]$.

In Malaysia, following the Restriction of Movement Order on 18 March 2020, the Ministry of Higher Education (MOHE) has announced the closure of higher education institutions. Educational activities needed to be carried out online for 1.2 million university students across the country [2]. In response to this, educators used various online applications and platforms to conduct teaching and learning activities throughout the period. It is of equal importance to evaluate OL readiness, enablers, and barriers from the students' perspective as this could lead to inequity issues in learning [5]. Hence, building from the above conceptual framework, we set out to measure relevant OL readiness components to students (systems and skills), self-regulation, enablers, and barriers to OL at home among medical students during the COVID-19 pandemic.

\section{Materials and Methods}

\subsection{Study Design}

In view of the pandemic context that may create a novel learning experience, we adopted a mixed-method explanatory sequential design $[17,18]$. We conducted a crosssectional study to measure the system (types of Internet connectivity, learning device owned by students, and perceived support on OL), skills (accessibility and familiarity with various OL platforms), levels, and significant associations of self-regulation in OL among medical students during COVID-19 pandemic. Through a descriptive phenomenological approach, we then explored the enablers and barriers to OL at home through the experience of medical students using semi-structured in-depth interviews (IDI) to explain the quantitative data. This study received ethical clearance from the institutional Human Research Ethics Committee Universiti Sains Malaysia (USM/JEPeM/COVID19-55). 


\subsection{Participants}

The sampling frame consisted of 545 medical students from Universiti Sains Malaysia (USM) Health Campus. Prior to the COVID-19 pandemic, all teaching and learning activities were conducted on campus as it relied heavily on practical sessions and patients contact. However, all teaching and learning activities were immediately changed to full OL following the Restriction of Movement Order. After the announcement of the Recovery Movement Control Order (RCMO) on 10 June 2020, the institution has allowed medical students to return in multiple phases with priorities given to Year 5 students while the remaining students had their teaching and learning activities online until 3 January 2021. Based on the Krejcie and Morgan table, the sample size required for this population size and $15 \%$ non-response rate was 266. Using convenience sampling, we invited Year 1 to Year 4 medical students to participate in the cross-sectional study through an open invitation in students' WhatsApp groups [19]. In our curriculum, Year 1 and Year 2 students are the pre-clinical students, while the Year 3, Year 4, and Year 5 students are the clinical students.

The sample size for the IDI was guided by the saturation principle [20]. Based on factors such as focused research question, homogenous participants, permission to use shadow data (sharing of classmates experience), and trained interviewer, we estimated that 10 to 25 IDI were needed to achieve saturation [21]. We invited the participants using purposive sampling from the participants list in the cross-sectional study. All participation was voluntary, and informed consent was obtained from participants prior to the data collection.

\subsection{Instrument}

The instrument package included 3 parts. The first part was the sociodemographic questions, including the academic year, sex, race, cumulative grade point average (CGPA), area of residence, household income, scholarship status, number of siblings, learning space at home, challenges, and impact of OL faced at home. To examine the complex array of OL readiness components on systems and skills, the second part covered types of Internet connection at home, mobile and Wi-Fi speed, the impact of OL on Internet usage, types of learning device, and ownership. The second part also asked about the usefulness of received support received at home, desired support for OL, and accessibility and familiarity with OL platforms used in the teaching and learning process.

The third part of the instrument consisted of the Online Self-Regulated Learning Questionnaire (OSLQ). OSLQ is a validated 24-items instrument to measure self-regulation in an OL environment. It has 6 subdomains that are goal setting, task strategies, time management, environment structuring, help-seeking, and self-evaluation. It is answered against a 5-point Likert response (strongly agree to strongly disagree). The results were interpreted through the mean and standard deviation of its subscale. It has been validated with high internal consistencies (Cronbach alpha 0.90 and 0.67 to 0.90 at subscale level) and suitable fit indices [12]. The authors obtained permission from the scale developer prior to the data collection.

For the IDI, the researcher interviewed the participants using an open-ended piloted interview protocol. The protocol was developed based on the Guide on Conducting In-Depth Interviews [22]. The final questions were

1. How was your experience with OL at home?

2. How did OL at home help or not helping your study?

3. In what way you feel that OL at home could improve?

\subsection{Data Collection}

In line with the RCMO, we administered the survey using anonymous Google Forms between 3 November 2020 and 2 December 2020. There were no monetary incentives given, but the participants were given the option to know their own self-regulation scores. We conducted the IDI through phone calls at a time that was convenient to the participants. The IDI was conducted by Author 1, who had no supervisory or authoritative role to the 
students. The conversation was transcribed verbatim, and each participant was assigned a pseudonym to maintain anonymity and confidentiality. Each IDI participant was given an RM20 stationary voucher as an incentive for their time.

\subsection{Data Analysis}

We applied descriptive statistics to describe the distribution of Internet connectivity, learning devices and perceived support, and the level of accessibility and familiarity with OL platforms. As for OSLQ, we used an independent T-test to determine significant associations with sex, scholarship funding, and CGPA, and one-way ANOVA to determine significant associations with the academic year, study area, broadband, and Wi-Fi speed. The analyses were carried out using SPSS version 27 (IBM Corp., Armonk, NY, USA).

We analyzed the qualitative data using a six-step thematic analysis in Atlas.Ti version 8.1 (Atlas.Ti GmbH, Berlin, Germany). Author 1 open-coded the raw data and organized the open-coding into the theme. Author 2 reviewed the themes, and their agreement was generally concordant. To enhance the trustworthiness of the findings, we applied coderecode procedure and data sources triangulation with the cross-sectional study findings.

\section{Results}

\subsection{Cross-Sectional Study: Demographic Data}

A total of 178 students participated in the survey, with a response rate of $78.8 \%$. Most of the participants were first-year $(40.4 \%)$, female $(79.2 \%)$, Malay $(71.9 \%)$, had a CGPA of $3.50-4.00(36.5 \%)$, stayed in an urban area $(67.4 \%)$, from the middle-income group $(42.7 \%)$, received a scholarship $(83.7 \%)$, and had OL at home in their bedroom (65.2\%) (Table 1).

Table 1. Summary of demographic data.

\begin{tabular}{cc}
\hline Demographic Variable $(\boldsymbol{n = 1 7 8 )}$ & $\boldsymbol{n} \mathbf{( \% )}$ \\
\hline Academic year & $72(40.4)$ \\
Year 1 & $32(18.0)$ \\
Year 2 & $42(23.6)$ \\
Year 3 & $32(18.0)$ \\
Year 4 & \\
Sex & $37(20.8)$ \\
Male & $141(79.2)$ \\
Female & \\
Race & $128(71.9)$ \\
Malay & $27(15.2)$ \\
Chinese & $14(7.9)$ \\
Indian & $5(2.8)$ \\
Others: Malaysians & $4(2.2)$ \\
\hline Others: International students & $65(36.5)$ \\
CGPA & $40(22.5)$ \\
3.50-4.00 & $1(0.6)$ \\
3.00-3.49 & $72(40.4)$ \\
2.67-3.00 & \\
Low income (bottom 40\%) & $120(67.4)$ \\
Hiddle income (middle 40\%) & $58(32.6)$ \\
\hline income (top 20\%) & $71(39.9)$ \\
Area of residence & $76(42.7)$ \\
Urban & $31(17.4)$ \\
Rural &
\end{tabular}


Table 1. Cont.

\begin{tabular}{cc}
\hline Demographic Variable $(\boldsymbol{n = 1 7 8 )}$ & $\boldsymbol{n} \mathbf{( \% )}$ \\
\hline Scholarship & $29(16.3)$ \\
Self-funded & $149(83.7)$ \\
Receiving scholarship & \\
\hline Number of siblings & $73(41.0)$ \\
$1-3$ & $105(59.0)$ \\
More than 3 & \\
Study area at home & $22(12.4)$ \\
Study room & $116(65.2)$ \\
Bedroom & $40(22.5)$ \\
Shared area &
\end{tabular}

\subsubsection{Internet Connectivity and Device}

The most used Internet connection at home was mobile broadband ( $80.4 \%)$, followed by home Wi-Fi (78.1\%) and public Wi-Fi (12.4\%). Most participants had multiple data subscriptions with fourth-generation (4G) mobile broadband speed (71.9\%). However, as for $\mathrm{Wi}-\mathrm{Fi}$, many participants enjoyed a speed of less than 50 megabits per second (33.1\%). To accommodate for OL needs, participants had to obtain additional Internet subscriptions $(30.9 \%)$, upgraded the current plan to a higher data plan $(17.4 \%)$, or changed to a different telco provider $(9.0 \%)$.

Most participants owned more than one OL device. Laptop (91.6\%) and smartphone $(88.8 \%)$ were the most used devices for online learning. Of the participants, $90.4 \%$ had the device for themselves, while $9.6 \%$ were sharing the device with other family members at home (Table 2).

Table 2. Types of Internet connection and online learning devices used for online learning at home.

\begin{tabular}{cc}
\hline Internet Connectivity and Device $(\boldsymbol{n = 1 7 8 )}$ & $\boldsymbol{n} \mathbf{( \% )}$ \\
\hline Types of Internet connection at home & $139(78.1)$ \\
Home Wi-Fi & $143(80.4)$ \\
Mobile broadband & $22(12.4)$ \\
Public Wi-Fi & \\
Wi-Fi speed at home & $37(20.8)$ \\
51-100 mbps & $43(24.2)$ \\
Less than 50 mbps & $59(33.1)$ \\
No Wi-Fi & $39(21.9)$ \\
\hline More than 100 megabits per second (mbps) & $128(71.9)$ \\
Fourth generation (4G) & $18(10.1)$ \\
Third generation (3G) & $1(0.6)$ \\
Enhanced data GSM evolution (EDGE) & $11(6.2)$ \\
High speed packet access (HSPA) & $20(11.2)$ \\
None & \\
Impact of OL on Internet usage & $55(30.9)$ \\
Additional subscription & $16(9.0)$ \\
Change of telco & $31(17.4)$ \\
Plan upgrade & $71(39.9)$ \\
\hline None &
\end{tabular}


Table 2. Cont.

\begin{tabular}{cc}
\hline Internet Connectivity and Device $(\boldsymbol{n = 1 7 8 )}$ & $\boldsymbol{n ( \% )}$ \\
\hline Devices used for OL & \\
Desktop & $7(3.9)$ \\
Laptop & $163(91.6)$ \\
Smartphone & $158(88.8)$ \\
Tablet & $83(46.6)$ \\
None & $0(0)$ \\
\hline Ownership of the main device & $161(90.4)$ \\
Self & $17(9.6)$ \\
Shared with siblings or parents & $0(0)$ \\
Loan
\end{tabular}

\subsubsection{Support}

The main challenges reported by the participants were distraction by non-academic matters, needed to help with house chores, lack of personal space to study, and needed to mind younger siblings (Table 3 ). Of the participants, $78.7 \%$ reported low productivity when compared to face-to-face learning, and $4.5 \%$ had to return earlier to the campus.

Table 3. Challenges faced at home and perception on support for online learning.

\begin{tabular}{cc}
\hline Challenges, Impact, and Support for OL & $n \mathbf{( \% )}$ \\
\hline Challenges faced in home environment during OL & \\
Distraction by non-academic matters & $145(81.4)$ \\
Lack of personal space to study & $81(45.5)$ \\
Need to help with house chores & $98(55.1)$ \\
Need to mind siblings & $76(42.7)$ \\
None & $9(5.1)$ \\
Impact of OL & $140(78.7)$ \\
Low productivity as compared to face-to-face teaching & $8(4.5)$ \\
Early return to campus & $30(16.9)$ \\
None & \\
Received helpful support & $89(80.9)$ \\
University IT team $(n=110)$ & $148(97.4)$ \\
Educators $(n=152)$ & $160(89.9)$ \\
Parents $(n=169)$ & $97(70.8)$ \\
Telco provider $(n=137)$ & $98(81.0)$ \\
Top management $(n=121)$ & \\
Desired support during OL & $159(89.3)$ \\
Free Internet data & $169(94.9)$ \\
Technology device loan & $104(58.4)$ \\
Increase Internet speed in residence & $166(93.3)$ \\
\hline Use of online platforms that are easier to access &
\end{tabular}

The majority of the participants looked for some support during the OL period. Of participants, $97.4 \%$ perceived helpful support from the educators, $89.9 \%$ perceived helpful support from their parents, $80.9 \%$ perceived helpful support from the institution technical team, $81.0 \%$ perceived helpful support from the institution's top management. However, only $70.8 \%$ perceived helpful support from the telco providers.

As for the future online learning duration home, desired support includes increased Internet speed at their residence $(94.9 \%)$, use of OL platforms that require less Internet speed $(93.3 \%)$, free Internet data $(89.3 \%)$, and device loan $(58.4 \%)$. 


\subsubsection{OL Platforms}

The majority of the participants had experienced OL with the listed platforms in Table 4. Based on the mean score, the platforms that were easiest to access (in terms of Internet connectivity) were WhatsApp, Telegram, and YouTube. In contrast, the platforms that were most difficult to access were Skype, Zoom, and Google Meet. As for user familiarity, the highest-rated platforms were WhatsApp, YouTube, E-Learning, and Telegram.

Table 4. Mean score for accessibility and familiarity of various online learning platforms.

\begin{tabular}{ccccc}
\hline \multirow{2}{*}{ Online Learning Platform } & \multicolumn{2}{c}{ Accessibility } & \multicolumn{2}{c}{ Familiarity } \\
\cline { 2 - 5 } & Mean & SD & Mean & SD \\
\hline E-mail & 3.30 & 0.73 & 3.44 & 0.67 \\
E-learning & 3.24 & 0.75 & 3.51 & 0.58 \\
Google Classroom & 3.07 & 0.81 & 3.19 & 0.75 \\
Google Drive & 3.18 & 0.78 & 3.50 & 0.60 \\
Google Meet & 3.04 & 0.82 & 3.21 & 0.73 \\
Kahoot! & 3.10 & 0.78 & 3.39 & 0.69 \\
Microsoft Teams & 3.06 & 0.86 & 3.26 & 0.73 \\
Skype & 3.09 & 0.85 & 3.25 & 0.74 \\
Telegram & 2.72 & 0.96 & 2.89 & 0.90 \\
Quizziz & 3.38 & 0.70 & 3.51 & 0.61 \\
YouTube & 3.14 & 0.76 & 3.29 & 0.75 \\
WhatsApp & 3.36 & 0.71 & 3.61 & 0.54 \\
WebEx & 3.59 & 0.57 & 3.66 & 0.56 \\
Zoom & 3.22 & 0.78 & 3.44 & 0.67 \\
\hline
\end{tabular}

3.1.4. Self-Regulation in Online Learning Environment and Associations with Relevant Demographic Variables

Each of the self-regulation domains had a mean higher than 3 for all Year 1-4 participant subgroups. Year 1 participants had the highest mean for environment structuring, goal setting, time management, help-seeking, and overall scale when compared to the other academic year groups. However, Year 2 participants had the highest mean for the task strategies domain, and Year 3 participants had the highest mean for the self-evaluation domain (Table 5).

Table 5. Mean Online Self-Regulated Learning Questionnaire (OSLQ) score for domains of self-regulation in an online learning environment for different academic year groups.

\begin{tabular}{ccccccc}
\hline & $\begin{array}{c}\text { Environment Structuring } \\
\text { Mean (SD) }\end{array}$ & $\begin{array}{c}\text { Goal Setting } \\
\text { Mean (SD) }\end{array}$ & $\begin{array}{c}\text { Time Management } \\
\text { Mean (SD) }\end{array}$ & $\begin{array}{c}\text { Help Seeking } \\
\text { Mean (SD) }\end{array}$ & $\begin{array}{c}\text { Task Strategies } \\
\text { Mean (SD) }\end{array}$ & $\begin{array}{c}\text { Self-Evaluation } \\
\text { Mean (SD) }\end{array}$ \\
Mean (SD)
\end{tabular}

As summarized in Table 6, there was a statistically significant association between Online Self-Regulated Learning Questionnaire (OSLQ) mean with the academic year as determined by the one-way ANOVA test with medium to large effect sizes. Post hoc comparisons (Tukey test) revealed that the pre-clinical mean OSLQ score was significantly higher than clinical year participants for environment structuring, goal setting, helpseeking, and overall score. Participants who had high CGPA had significantly higher goal setting and self-evaluation OSLQ scores. Participants who had a designated study room were found to have higher goal setting when compared to those learning in a shared area at home. However, there was no significant mean difference between those who studied in a designated study room and their bedroom and those who studied in their bedroom 
and a shared area. We found no significant association between OSLQ scores with sex, scholarship funding, broadband, or Wi-Fi speed.

Table 6. Significant mean difference of OSLQ scores across relevant variables.

\begin{tabular}{|c|c|c|c|c|c|c|}
\hline Variable & OSLQ Domain & Significant Pair & $T$ or $F$ & Mean Difference & $p$-Value & $\begin{array}{r}\text { Effect Size } \\
\text { (Partial } \eta 2)\end{array}$ \\
\hline \multirow[t]{9}{*}{ Academic year } & Environment structuring & Year 1-Year 3 & 14.204 & 0.494 & 0.003 & \\
\hline & & Year 1-Year 4 & & 0.942 & $<0.001$ & 0.197 \\
\hline & & Year 2-Year 4 & & 0.178 & $<0.001$ & \\
\hline & Goal setting & Year 1-Year 4 & 4.440 & 0.470 & 0.006 & 0.071 \\
\hline & Help seeking & Year 1-Year 3 & 9.814 & 0.410 & 0.028 & \\
\hline & & Year 1-Year 4 & & 0.839 & $<0.001$ & 0.145 \\
\hline & & Year 2-Year 4 & & 0.641 & 0.004 & \\
\hline & Overall & Year 1-Year 3 & 7.151 & 0.264 & 0.048 & \\
\hline & & Year 1-Year 4 & & 0.494 & $<0.001$ & 0.110 \\
\hline \multirow[t]{2}{*}{ CGPA } & Goal setting & Above-below 3.50 & 2.244 & 0.291 & 0.027 & 0.095 \\
\hline & Self-evaluation & Above-below 3.50 & 2.127 & 0.293 & 0.036 & 0.106 \\
\hline Study area & Goal setting & Designated study room—shared area & 5.451 & 0.583 & 0.003 & 0.059 \\
\hline
\end{tabular}

\subsection{In-Depth Interview}

A total of 15 students volunteered for the IDI, and the researcher arranged a phone interview session at their convenient time. Saturation was achieved after interviewing 10 participants from various backgrounds (Table 7).

Table 7. Distribution of IDI participants based on relevant demographic data.

\begin{tabular}{cc}
\hline Demographic Variable $(\boldsymbol{n = 1 0 )}$ & $\boldsymbol{n} \mathbf{( \% )}$ \\
\hline Academic year & \\
Pre-clinical students & $5(50)$ \\
Clinical students & $5(50)$ \\
Race & \\
Malay & $6(60 \%)$ \\
Chinese & $1(10 \%)$ \\
Indian & $1(10 \%)$ \\
Others: Malaysian & $1(10 \%)$ \\
International student & $1(10 \%)$ \\
Sex & $3(30)$ \\
Male & $7(70)$ \\
Female & \\
Residence & $8(80)$ \\
Urban & $2(20)$ \\
Rural &
\end{tabular}

\subsubsection{Benefits of Online Learning}

Time saving emerged as the most cited theme under the benefits of OL. Participants proposed that OL reduced the traveling time and provided them more time to take up other undertakings.

"It (OL) is perfect because I can do so many things in one time. I can join the lectures, participates in workshops, learn another language or new hobbies like interior design or yoga or poems. Actually, I didn't think it was going to be this great, but now I am enjoying it." (Year 1, international student, male)

Other themes include increased formal teaching sessions, getting more study resources, and being closer to family support.

"When we were in wards (before OL), it was mainly self-directed learning. I agree that OL gave us less clinical experience, but we gained more theoretical input as our supervisors took us in small groups and we were able to interact better." (Year 4, local student, female) 


\subsubsection{Disadvantages of Online Learning}

Many participants proposed that OL provided a less clinical experience for clinical students and practical experience for pre-clinical students. Students described having simulated patients during online clerking as a suitable alternative but did not provide them with adequate exposure to become competent doctors.

"Our worry is we will become the OL version of medical graduates-lack of experience, lack of communication skills in patient care because it's just not the same when you clerk online. We got to clerk only one patient for each posting because you cannot get many patients in every online classes." (Year 4, local student, female)

"I wanted to practice and touch the anatomy models because they look just the same online. I am in dire to return to campus and learn in the anatomy museum because we don't have all that (at home)." (Year 2, local student, female)

Participants also described having to spend more time revisiting the recorded session following Internet connection problems or lack of focus. Students also described this consumed more time not just to those who experience glitches but to other classmates who have to explain the content to them.

"A few days ago, there was somebody having internet problem and missed the discussion. After the Problem Based Learning ended, we had to tell her again the whole thing while she was being distracted by her brother and sister." (Year 1, local student, female)

Other themes that emerged under disadvantages include struggling to sustain focus in OL (following lack of clinical experience to make sense of the content), physical impact (dry eyes and back pain from prolonged screen time), less adaptability for kinesthetic learners, having to spend more money on Internet data, connection problems during the examination and reduced motivation from uncertainties of OL.

"We do study groups, but the pace is much slower now. Everyone was eagerly waiting to return to campus. Once we were allowed to return but there were sudden RMO notice close to the return date. These uncertainties affected our drive to study." (Year 4, local student, male)

\subsubsection{Enablers of Online Learning}

A total of 15 themes emerged under enablers of OL and can be categorized into learners, educators, and institutions (Figure 1). As for learners, the most cited theme is selfregulation. Participants described that self-discipline to follow the OL routine, maintaining focus, setting individual goals in learning and striving to achieve the goals, knowing where to find help, and helping friends in need as enablers in OL.

"I read some textbook because nothing parallels textbook. For example, if we are having anatomy or connective tissue classes that day, I will read the textbook and if I need clarification, I will find some video because there are many videos now on YouTube." (Year 1, international student, male)

"When we missed something from the online class, we will ask in the WhatsApp group. That group really helps when we don't understand something, we will just ask there. And we help by filling out other's gap too." (Year 3, local student, female)

Home environment emerged as the most cited theme after self-regulation. Participants proposed that having a conducive home environment and learning space is an important enabler to help their focus. Participants also proposed having their own learning gadget and suitable Internet connection as enablers for OL. 
"I had a lot of distractions at home because my mom is a nanny. She had several babies to mind and these babies cry during lectures. Luckily, I have good internet connection at home. (But) I have to spend extra RM100 every month to get that kind of connection." (Year 4, local student, female)

As for educators, the most cited theme is educators' presence. Participants described that educators' connection with learners physically (by interacting through webcam) or mentally (through questions and answers session) helped learners to engage more with the session.

"I know it's different from seeing them (educators) physically, but I can still see them in OL so this made the learning experience more natural." (Year 1, international student, male)

Themes on the conduct of OL include active learning, authentic learning experience, planning of session with proper cognitive load, use of user-friendly OL platforms, familiarity with OL platforms, and providing ways for students to verify information.

"It's the balance between the length and content. The good one will be the shorter class because students can only focus for 30 to $45 \mathrm{~min}$ and we need short break after that. Lecturers can split the heavy topics into several sessions." (Year 1, international student, male)

"Some lecturers brought patients during the online classes. Everyone gets to clerk the patient just like in the wards. That was a really good session." (Year 4, local student, female)

"Sometimes the lecturers wanted to incorporate activities, but they are not familiar. There was once a lecturer wanted to play some video but there was no sound and she spent so much time on that. The lecturer had to get help from students to set that up." (Year 1, local student, female)

Participant also proposed the use of the asynchronous approach as a complement to synchronous input to accommodate students with a poor connection. The total reliance on the synchronous approach may also impose some difficulties on students from different time zones.

"I prefer asynchronous because sometimes students have internet problems and we missed out. If it was asynchronous, we could join the class when our internet is more stable." (Year 1, local student, female)

"Most classes start at like 8am Malaysia time, so I have to wake up at 2.30 a.m. here." (Year 1, international student, male)

Themes of OL institutional enablers are providing educational resources for students (such as free access to the relevant educational website), suitable Internet connection for lecturers to conduct OL, and support for students who could not afford a suitable Internet connection.

"There were times where lecturers had internet connection problems and the class paused for $30 \mathrm{~min}$, we all had to enter the WebEx room again." (Year 1, local student, female)

"We need some portable Wi-Fi device. Some of us can only learn in campus because of poor internet coverage at our home." (Year 3, Local student, Male)

"I wish the university can provide wireless microphone to lecturers when they have to do online demonstration. Sometimes the audio quality is very poor because they were far from the laptop internal microphone (when doing demonstration)." (Year 3, local student, male) 


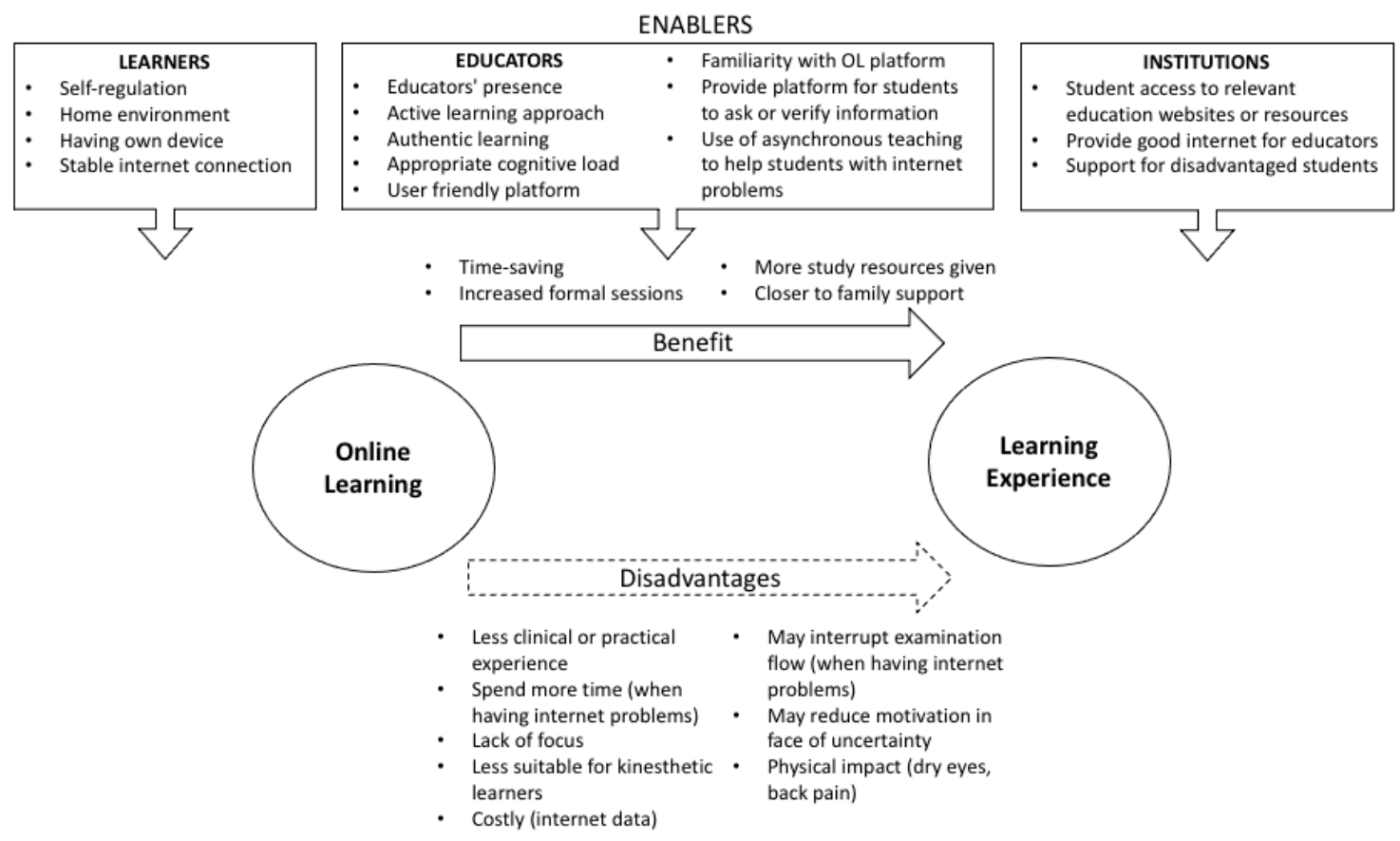

Figure 1. Conceptual model of enablers of online learning in the medical curriculum.

\section{Discussion}

The response rate in the cross-sectional study was high and exceeded the recommended response rate for a survey study [23]. Most of the participants' demographics corresponded to the population demographic distribution, except there were more Year 1 and female students. The most significant finding from the demographic data was $22.5 \%$ of students did not have a learning space at home, and $45.5 \%$ of the students perceived the lack of personal learning space as a challenge in OL. A study from India found that $44.4 \%$ of its university students did not have a designated study room, and $12.6 \%$ perceived an unfavorable home environment as a challenge to OL [24]. Educational institutions often pay huge consideration in designing their physical learning space as it is linked to a better learning experience and successful outcomes [25]. Learning space is also integral in minimizing distractions [26], and this is evident in our study that found significantly higher self-regulation among students who learned in a designated space as compared to those learning in a shared area. Optimizing learning space may be difficult to achieve in individual students homes. However, understanding this may guide educators to design OL approach that put suitable demand on the home learning environment such as asynchronous mode and longer assignment deadlines [27].

In contrast to studies from other countries that proposed that not all students have personal learning devices $[3,28]$, this study found that all students owned at least one learning device. This corresponds to the MCMC report that found $98.2 \%$ of Malaysians had smartphones and 71.3\% had personal computers [9]. However, some students did not have Wi-Fi or mobile broadband coverage at home, and $60.1 \%$ had to either upgrade their current plan, subscribe to an additional plan, or change to a new telco. This highlights Internet connection as a major challenge in OL as compared to learning device ownership in this population. Another study among local college students found that many had Internet access problems at home and could not afford Internet subscription [29]. Although some service providers have been proactive in giving $1 \mathrm{~GB}$ of free data to students, accessibility issues were still unresolved [30]. The MCMC report revealed a considerable difference in Internet speed between service providers and states in Malaysia. A local study reported that $12.2 \%$ of students mobilized around 1 to $2 \mathrm{~km}$ from their house to obtain a stable Internet connection [31]. Although our study found no significant association between Internet speed and self-regulation in OL, another local study reported that 
Internet access problems prevented students from completing online learning activities and submitting assignments [2].

Despite the increasing use of live video conferencing applications such as WebEx, Zoom, and Google Meet [32], it is interesting to note that messenger applications such as WhatsApp, Telegram, and YouTube appeared to be the most accessible and easiest platforms to navigate in OL. In one of the useful frameworks comparing OL platforms based on bandwidth demand and immediacy, group chat and messaging applications are categorized as the practical platforms that offer immediate educator-students interaction with less Internet speed requirement [33]. YouTube application, on the other hand, provides educators the opportunity to share demonstration or lecture videos that it is accessible when students have a stable Internet connection. This corresponds with the IDI findings where students proposed an asynchronous approach as alternative teaching strategies to promote greater social inclusivity of learners in OL [27].

Researchers have agreed that self-regulation skill is more important in the OL as it is more autonomous as compared to the face-to-face learning environment [12,34]. Domains of self-regulation such as goal setting, self-evaluation, and help-seeking encourage students to examine, reflect and communicate about their learning and predicted their persistence in OL [35]. A local study among private university students also found that self-regulation significantly predicted satisfaction in OL [36]. In this study, we found suitable self-regulation in OL among medical students. However, contrary to our expectation, the pre-clinical students had significantly higher self-regulation as compared to the senior clinical year students. A local modeling study found that the effect of peer learning on OL satisfaction is fully mediated by self-regulation [37], and this may have helped our first-year students who had never physically meet their peers during the OL.

Our qualitative findings generated a conceptual model of enablers in OL at the students, educators, and institutional levels. This model is consistent with a framework that categorized the themes of OL research into learners, course and instructor, and organization [38]. At the students' level, students should be equipped with various self-regulation strategies to help them take more ownership and control of their learning process [36]. This is important as most of the participants quoted distraction to non-academic matters as the main challenge to OL at home. Another important enabler is a stable Internet connection. A more collaborative effort with the government, education institutions, and telco providers are desirable, and actions may include zero-rating or cost-free access to educational materials, bandwidth shaping, free SIM cards, data caps lift, and public hotspots to increase connectivity [39]. In fact, the majority of the students from the present study perceived free data and increased Internet speed as a useful aid to support OL in the longer run.

Studies found that educators favored traditional classroom mode as compared to OL due to lack of interaction, difficulty to sustain students' attention, and technical glitches [32]. Some instructors felt that they were not equipped with the required skills to transition into OL in a short period of time [3]. The themes that emerged at the educators' level provide a useful guide for faculty development to sustain OL in the longer run. As anatomy practical and patient contact are integral in medical training, educators need to be exposed to OL teaching aids that could enhance authentic learning. Faculty development should not just focus on training relevant pedagogical strategies in technology-mediated learning $[40,41]$ but also encourage educators to create content that is suitable in terms of cognitive load and use platforms that require less bandwidth to accommodate students with poor Internet access.

The success of OL does not just depend on learners or educators but also on the institution [38]. Both cross-sectional and IDI findings proposed the need for an educational institution to take proactive measures in supporting students with poor Internet access and home environment. In this sample, $4.5 \%$ of students were not able to sustain OL at home and were allowed to return to campus with appropriate COVID-19 standard operating procedures. The findings also highlight that educators need to be supported by competent technology departments, trainers, and infrastructures. As OL became the mainstream of 
teaching and learning and consumed more preparation time, tenure and promotion must be redesigned to be more aligned with the educators' workload [7].

Our study has a number of limitations. The nonprobability sampling applied in this study limits the generalizability of the findings to a wider context. The participants had more Year 1 students as compared to the other batches, and the absence of prior face-toface teaching experience could have affected their experience on OL. We only assessed OL enablers from the learners' perspective. Despite the limitations, the findings provide some overview of enablers of OL and practical framework to guide immediate actions in sustaining OL. Future studies are desirable to examine other stakeholders' (such as educators, top management personnel, and public) input to OL enablers. As self-regulation becomes more critical in the OL context, future studies could explore ways to enhance self-regulation learning strategies in an unstructured learning environment. More research is also needed to explore ways to increase the effectiveness of OL in various learning styles, especially kinaesthetic learners.

The study found that an inconducive home environment and poor Internet connection as significant barriers to OL among medical students in this institution. Despite these barriers, students showed a suitable self-regulation level in OL. The qualitative analysis produced a conceptual model highlighting several enablers to OL at the learners, educators, and institution levels. The fact that the COVID-19 pandemic trajectory is yet unknown, immediate actions are necessary to provide adequate Internet connection and support to learners and educators. More research is also desirable to look into a more sustainable OL that promotes inclusivity and the impact of OL on learning outcomes attainment and learners' and educators' wellbeing.

Author Contributions: Conceptualization and methodology, A.S.H. and N.S.R.; data collection and formal analysis, N.S.R.; writing—original draft preparation, review, and editing, A.S.H. and N.S.R. All authors have read and agreed to the published version of the manuscript.

Funding: This research received no external funding.

Institutional Review Board Statement: This study was conducted according to the guidelines of the Declaration of Helsinki and approved by the Human Research Ethics Committee Universiti Sains Malaysia (COVID19-55).

Informed Consent Statement: Informed consent was obtained from all subjects involved in the study.

Data Availability Statement: The data presented in this study are available on request from the corresponding author.

Conflicts of Interest: The authors declare no conflict of interest.

\section{References}

1. Moore, J.L.; Dickson-deane, C.; Galyen, K. Internet and Higher Education e-Learning, online learning, and distance learning environments : Are they the same ? Internet High. Educ. 2011, 14, 129-135. [CrossRef]

2. Kamal, A.A.; Shaipullah, N.M.; Truna, L.; Sabri, M.; Junaini, S.N. Transitioning to online learning during COVID-19 Pandemic: Case study of a Pre-University Centre in Malaysia. Int. J. Adv. Comput. Sci. Appl. 2020, 11, 217-223. [CrossRef]

3. Hallal, K.; Hajjhussein, H.; Tlais, S. A Quick Shift from Classroom to Google Classroom: SWOT Analysis. J. Chem. Educ. 2020, 1-4. [CrossRef]

4. World Health Organization. WHO Announces COVID-19 Outbreak a Pandemic [Internet]. 2020. Available online: https: //www.euro.who.int/en/health-topics/health-emergencies/coronavirus-covid-19/news/news/2020/3/who-announcescovid-19-outbreak-a-pandemic (accessed on 20 April 2021).

5. Langenfeld, T. Internet-Based Proctored Assessment: Security and Fairness Issues. Educ. Meas. Issues Pract. 2020, 39, 24-27. [CrossRef]

6. Alshaher, A.A.-F. The Mckinsey 7S Model Framework for E-Learning System Readiness Assessment. Int. J. Adv. Eng. Technol. 2013, 6, 1948-1966.

7. Ebner, M.; Schön, S.; Braun, C.; Ebner, M.; Grigoriadis, Y.; Haas, M.; Leitner, P.; Taraghi, B. COVID-19 epidemic as E-learning boost? Chronological development and effects at an Austrian university against the background of the concept of "E-learning readiness". Futur. Internet 2020, 12, 94. [CrossRef]

8. Neuwirth, L.S.; Jović, S.; Mukherji, B.R. Reimagining higher education during and post-COVID-19: Challenges and opportunities. J. Adult Contin. Educ. 2020. [CrossRef] 
9. Malaysian Communications and Multimedia Commission. Network Performance Report 2019; Malaysian Communications and Multimedia Commission: Cyberjaya, Malaysia, 2019.

10. Chung, E.; Subramaniam, G.; Dass, L.C. Online Learning Readiness among University Students in Malaysia amidst COVID-19. Asian J. Univ. Educ. 2020, 19, 46-58. [CrossRef]

11. Suryaman, M.; Cahyono, Y.; Muliansyah, D.; Bustani, O.; Suryani, P.; Fahlevi, M.; Pramono, R.; Purwanto, A.; Purba, J.T.; Munthe, A.P.; et al. COVID-19 pandemic and home online learning system: Does it affect the quality of pharmacy school learning? Syst. Rev. Pharm. 2020, 11, 524-530.

12. Barnard, L.; Lan, W.Y.; To, Y.M.; Paton, V.O.; Lai, S.L. Measuring self-regulation in online and blended learning environments. Internet High. Educ. 2009, 12, 1-6. [CrossRef]

13. Zimmerman, B.J. Attainment of self-regulation: A social cognitive perspective. In Handbook of Self-Regulation; Academic Press: San Diego, CA, USA, 2000; pp. 13-39.

14. Lee, Y.; Choi, J.; Kim, T. Discriminating factors between completers of and dropouts from online learning courses. Br. J. Educ. Technol. 2013, 44, 328-337. [CrossRef]

15. Yukselturk, E.; Bulut, S. Predictors for student success in an online course. Educ. Technol. Soc. 2007, 10, 71-83.

16. Kassab, S.E.; Al-Shafei, A.I.; Salem, A.H.; Otoom, S. Relationships between the quality of blended learning experience, self-regulated learning, and academic achievement of medical students: A path analysis. Adv. Med. Educ. Pract. 2015, 6, 27-34. [CrossRef]

17. Creswell, J.W.; Clark, V.L.P. Complex Application of Core Mixed Methods Designs. In Designing and Conducting Mixed Methods Research; SAGE Publications Ltd: Thousand Oaks, CA, USA, 2018; pp. 168-220.

18. Johnson, R.B.; Onwuegbuzie, A.J. Mixed Methods Research : A Research Paradigm Whose Time Has Come. Educ. Res. 2004, 33, 14-26. [CrossRef]

19. Krejcie, R.V.; Morgan, D. Determining sample size for research activities. Educ. Psychol. Mzasurexent 1970, 30, 607-610. [CrossRef]

20. Mason, M. Sample Size and Saturation in PhD Studies Using Qualitative Interviews. Qual. Soc. Res. 2010, 11. [CrossRef]

21. Morse, J.M. Qualitative Health Research. Qual. Health Res. 2000, 10, 3-5. [CrossRef]

22. Boyce, C.; Neale, P. Conducting In-Depth Interviews: A Guide for Designing and Conducting In-Depth Interviews for Evaluation Input; Pathfinder International Tool Series. Available online: http://www.pathfind.org/site/DocServer/m_e_tool_series_indepth_ interviews.pdf?docID=6301 (accessed on 20 April 2021).

23. Baruch, Y.; Holtom, B.C. Survey response rate levels and trends in organizational research. Hum. Relat. 2008, 61, 1139-1160. [CrossRef]

24. Kapasia, N.; Paul, P.; Roy, A.; Saha, J.; Zaveri, A.; Mallick, R.; Barman, B.; Das, P.; Chouhan, P. Impact of lockdown on learning status of undergraduate and postgraduate students during COVID-19 pandemic in West Bengal, India. Child. Youth Serv. Rev. 2020. [CrossRef] [PubMed]

25. Ellis, R.A.; Goodyear, P. Models of learning space: Integrating research on space, place and learning in higher education. Rev. Educ. 2016, 4, 149-191. [CrossRef]

26. Irizarry, B.L. Oil Pulling : A Traditional Method on the Edge of Evidence. Dent. Hypotheses 2017, 11, 126-128. [CrossRef]

27. Arnou, C.; Cornelis, G.; Jan Heymans, P.; Howard, S.K.; Leemans, G.; Nuyens, I.; Tondeur, J.; Vaesen, J.; Van Den Driessche, M.; Elen, J.; et al. COVID-19 and Educational Spaces: Creating a Powerful and Social Inclusive Learning Environment at Home. Available online: https:/ / www.unesco-vlaanderen.be/media/2499/download/20200507EN_createalearningenvironmentathome2 .pdf? $\mathrm{v}=1$ (accessed on 20 April 2021).

28. Saif Almuraqab, N.A. Shall universities at the UAE continue distance learning after the CoviD-19 pandemic? Revealing students perspective. Int. J. Adv. Res. Eng. Technol. 2020, 11, 226-233.

29. Wan Hassan, W.A.S.; Ariffin, A.; Ahmad, F.; Sharberi, S.N.M.; Nor Azizi, M.I.; Zulkiflee, S.N. Covid-19 pandemic: Langkawi vocational college student challenge in using google classroom for teaching and learning (t\&l). Int. J. Adv. Trends Comput. Sci. Eng. 2020, 9, 3299-3307.

30. Palansamy, Y. Minister: Internet Connectivity for Students Being Worked on, Issue Is Access to Devices. Available online: https:/ /www.malaymail.com/news/malaysia/2020/06/17/minister-internet-connectivity-for-students-being-workedon-issue-is-access/1876414 (accessed on 22 April 2021).

31. Sim, S.P.-L.; Sim, H.P.-K.; Quah, C.-S. Online Learning: A Post Covid-19 Alternative Pedagogy For University Students. Asian J. Univ. Educ. 2021, 16, 137. [CrossRef]

32. Deepika, N. The impact of online learning during COVID-19: Students' and teachers' perspective. Int. J. Indian Psychol. 2020, 8, 784-793.

33. Standford, D. Videoconferencing Alternatives: How Low-Bandwidth Teaching Will Save Us All [Internet]. Center for Teaching and Learning, De Paul. 2020. Available online: https:/ / www.iddblog.org/videoconferencing-alternatives-how-low-bandwidthteaching-will-save-us-all/ (accessed on 16 April 2021).

34. Schwam, D.; Greenberg, D.; Li, H. Individual Differences in Self-regulated Learning of College Students Enrolled in Online College Courses. Am. J. Distance Educ. 2020. [CrossRef]

35. Stephen, J.S.; Rockinson-Szapkiw, A.J.; Dubay, C. Persistence Model of Non-traditional Online Learners: Self-Efficacy, SelfRegulation, and Self-Direction. Am. J. Distance Educ. 2020, 34, 306-321. [CrossRef]

36. Lim, C.L.; Jalil, H.A.; Ma'rof, A.M.; Saad, W.Z. Differences in Self-Regulated Learning (SRL) and Online Learning Satisfaction Across Academic Disciplines: A Study of a Private University in Malaysia. Int. J. Learn. Teach. 2020, 6, 62-67. [CrossRef] 
37. Lim, C.L.; Jalil, H.A.; Ma'rof, A.M.; Saad, W.Z. Self-regulated learning as a mediator in the relationship between peer learning and online learning satisfaction: A study of a private university in Malaysia. Malaysian J. Learn. Instr. 2020, 17, 51-75. [CrossRef]

38. Martin, F.; Sun, T.; Westine, C.D. A systematic review of research on online teaching and learning from 2009 to 2018. Comput. Educ. 2020, 159, 104009. [CrossRef]

39. Trucano, M. How Ministries of Education Work with Mobile Operators, Telecom Providers, ISPs and Others to Increase Access to Digital Resources during COVID19-Driven School Closures (Coronavirus) [Internet]. World Bank Blogs. 2020. Available online: https:/ / blogs.worldbank.org/education/how-ministries-education-work-mobile-operators-telecom-providers-ispsand-others-increase (accessed on 19 April 2021).

40. Anthony, B.; Kamaludin, A.; Romli, A.; Raffei, A.F.M.; Phon, D.N.A.L.E.; Abdullah, A.; Ming, G.L. Blended Learning Adoption and Implementation in Higher Education: A Theoretical and Systematic Review. Available online: https://link.springer.com/ article/10.1007/s10758-020-09477-z (accessed on 22 April 2021).

41. Lakhal, S.; Khechine, H.; Mukamurera, J. Explaining Persistence in Online Courses in Higher Education: A Difference-in-Differences Analysis; Springer International Publishing: Berlin/Heidelberg, Germany, 2021; Volume 18, ISBN 4123902100251. 